\title{
NGOs in Global Governance
}

\section{Securing Role through Engagement at the United Nations?}

\section{Case Study - Global Policy Forum}

Jaroslava Bobková

What is the role of NGOs at the United Nations, and, by extension, in global governance? With limited possibilities to measure it directly, this article adopts discursive analysis as an innovative approach to the issue. Analysis of three texts by Global Policy Forum represents an important insight into the question and a tool for further research. It shows that despite the relative increase of their participatory rights at the UN, NGOs seem to realise approaching a point of saturation in what they may demand from the UN in terms of their access and moderate the tone of writing accordingly. Drawing on Global Policy Forum's example, the article argues that NGOs at the UN appear to have transformed from entities begging for more access to its more equal partners. Most importantly, the article represents a blueprint for further research of role of actors in the international system.

Keywords: United Nations, non-governmental organisations, role, discursive analysis, Global Policy Forum.

Non-governmental organisations (NGOs) use different ways to enhance their global role, but engagement in intergovernmental organisations seems to be gradually standing out among them. Especially Engagement at the United Nations?. Case Study - Global Policy Forum. Central European Journal of International and Security Studies I4, no. I: 132-I58.

(C) 2020 CEJISS. Article is distributed under Open Access licence: Attribution NonCommercial 3.0 Unported (cc by-nc 3.0). 
with the emergence of global governance, intergovernmental organisations are becoming the centre of global policymaking in which not only governments participate, but increasingly also other stakeholders. This is especially true for the United Nations (UN), which is considered by some scholars ${ }^{\mathrm{I}}$ as the heart of global governance.

With gaining ground in global policymaking, NGOs prove that not only are they not prepared to act solely as implementers and observers of governments' decisions, but that they do not even need the governments to present their ideas on the global stage. Instead, NGOs participate at the UN and other intergovernmental organisations directly and use it also as leverage to strengthen their role further. In terms of their power within the UN, NGOs still lag behind states, yet their numbers and participatory rights are on the rise. ${ }^{2}$ But is their influence at the UN also rising? What is the role of NGOs within the UN, and, by extension, in global governance?

The issue of the role of NGOs at the UN has been solved only partially so far. Most studies have limited themselves to a mere description of historical and/or current access of NGOs to the UN, or some of its structures. ${ }^{3}$ Other studies operate with the notion of NGO role at the UN in an even more simplistic manner. ${ }^{4}$ A more analytical approach to the question has been taken by scholars interested in role of NGOs in a particular UN body and/or issue area. ${ }^{5}$ This study, however, aims at assessing the role of NGOs at the UN in a broader perspective, which goes beyond a mere summarisation of smaller-scale studies ${ }^{6}$ and overcomes some uncertainties regarding the causal relationships from which the smaller-scale studies derive the role of NGOs.

To do so, I eschew trying to estimate the proportion of NGOs' contribution to UN outcomes and employ instead a method of discursive analysis developed by Fairclough, ${ }^{7}$ through the perspective of which I analyse a selected body of texts on NGO access to and participation at the UN. A detailed discursive analysis allows me to better analyse the mutual (power) relations between NGOs and the UN, but also evolving self-perception of NGOs, both of which can be important indicators of the NGO role within the UN.

Though the main aim of the article is to present an alternative approach to measuring of the role of NGOs at the UN as a methodological concept, it does so in a practical way. It applies the approach to three carefully selected texts co-authored by an NGO called Global Policy Forum (GPF). In such a way, not only can I show the way how to 
perform the analysis by using this approach, but also test the feasibility of this alternative approach and its capacity to bring results.

$\mathrm{I}$ begin this article by examining the existing literature on the role of NGOs at the UN. On the basis of this brief overview, I clarify the

CEJISS way in which I propose to approach the issue. After elaboration of the I/2020 methodological apparatus, I turn to empirical data and present results of the discourse analysis to demonstrate what the GPF texts on NGO access to and participation at the UN can say about the role which NGOs achieve at this organisation. I conclude by discussing the results and evaluating the employed approach.

\section{Methods: How to measure the role of NGOs at the United Nations?}

Most studies on the role of NGOs at the UN remain mere descriptions of their status (participatory rights) at the UN. Only recently, some scholars have tried to take the study further to analyse the role of NGOs vis-à-vis other stakeholders by assessing the merits of NGOs at outcomes. This approach, inspired mainly by institutional theories, seems to be the only logical way to measure the role. However, such an approach does not allow for studying the role of NGOs at the UN in this broad perspective, and even in smaller-scale studies it encounters non-negligible difficulties. Decision-making processes at the UN are usually too complicated to allow for identifying the share which individual actors have in the final forms of decisions, or their mere existence. Decisions at the UN are generally adopted by its member states, but there are many aspects which influence their decision-making and it is practically impossible to trace them. ${ }^{8}$ Even NGOs are influencing states and their representatives in many different ways, from advocacy at home governments to direct confrontation at the UN premises, sometimes in different directions (influence by NGOs of diverging views). Consequently, their overall contribution to what is finally adopted is practically unmeasurable. It is also difficult to distinguish what has actually been achieved by NGOs from to what extent the final outcomes simply correspond to their preferences.

I base the alternative approach to this issue on constructivist ideas which pay more attention to social construction of (power) relations. In this perspective, 'role' can be understood as a result of discourses through which identities, social roles and mutual relations are constructed. ${ }^{9}$ The approach of social constructivism enables the study of 
the role of NGOs at the UN beyond what is institutionally prescribed to them, to assess also the socially constructed component of the role in line with the integrated version of role theory, and to assess the role also in relation to the role of other actors (cf. Stryker and Statham). ${ }^{\text {Io }}$ The use of discursive analysis helps me to assess the role of NGOs at the UN without trying to directly analyse their real contributions to UN outcomes.

I define the role of NGOs at the UN as a position which NGOs achieve at this organisation. This concept is somewhat similar to the idea of influence but it is wider in that it does not necessarily limit itself to what NGOs achieve at the UN in terms of their share in decision-making, for it also includes perception of their importance for the organisation. ${ }^{\text {II }}$ The notion of role is also close to the concept of power, for it reflects, to some extent, the relative distribution of power in the relationship. In this regard, added value of the analysis of discourse lies also in its capacity to discover some signs of power that are hidden in or behind the discourse. According to Fairclough ${ }^{\mathrm{I} 2}$ discourse is a 'place where relations of power are actually exercised and enacted'. Generally speaking, analysis of discourse has the power to reveal power and with that also roles of more and less powerful social actors on whom the discourse elaborates.

In this study, I focus on analysis of discourse on NGO access to and participation at the UN. Even though some elements of the socially constructed role of NGOs at the UN can be found in other texts as well, texts on NGO access to and participation at the UN directly construct them. The question of NGO access is a determinant for assessing their role at the UN. Not only could we hardly speak of any role if NGOs were not present at the UN, but their presence and visibility are the actual reasons why we consider a possible role for them in the organisation. At the same time, however, it is not possible to deduce the role of NGOs simply from the width of their participatory rights at the UN. ${ }^{13}$ That would imply the assumption that access of NGOs to the UN is something for what they fight themselves, whilst the other actors, be it member states or the UN secretariat, are pushing for the opposite, i.e. for restriction of NGO access to the organisation. This would completely overshadow reasons for which the UN is willing to open itself. ${ }^{14}$ Rather than focusing on advancements in access mentioned in analysed texts, it is important to concentrate on how the discourse is built and what kind of role for NGOs can be derived from it indirectly. 
It is thus not only the question of content, but especially of format of the discourse.

With this in mind, I employ the discourse analysis approach developed by Fairclough. ${ }^{15}$ Fairclough proposes focusing discourse text

CEJISS analysis on twelve areas: (I) social events of which the analysed text is I/202O a part; (2) genres used in the text; (3) text's orientation towards difference; (4) intertextuality; (5) use of existential, propositional and value assumptions; (6) predominant semantic and grammatical relations between sentences and clauses; (7) substance of exchanges presented by the text, speech functions and grammatical mood; (8) use of discourses; (9) ways of social events representation; (Io) style of the text; (II) use of epistemic and deontic modalities and (I2) expressions of evaluation.

I conducted this detailed discourse analysis for three texts authored or co-authored by Global Policy Forum, an NGO which has promotion of NGO participation at the UN as one of its main objectives. I explain the choice of texts in the next section. After having analysed each of the texts separately according to the points above, I made a comparison of the three texts for each of the twelve areas and finally, I drew some conclusions on the role of NGOs at the UN from consideration of the findings across these areas. The research question which $\mathrm{I}$ have pursued through this analysis can be formulated as follows: How is the role of NGOs at the $\mathrm{UN}$ formulated in their discourse on access to and participation at the UN?

\section{Choice of texts}

As the Fairclough' ${ }^{16}$ discourse analysis approach demands deep, thorough and very comprehensive study of each piece of the analysed discourse, I have chosen three shorter texts for my analysis (see Table I). These three texts are elaborated, or at least co-authored, by NGO called Global Policy Forum (GPF) and published on its websites. ${ }^{17}$

GPF is an NGO that has been very active in promoting access of NGOs to the UN since the early I990s, when the issue arose, and remains one of its main proponents till now. ${ }^{18} \mathrm{GPF}$ claims to be 'an independent policy watchdog that monitors the work of the United $\mathrm{Na}$ tions and scrutinizes global policymaking [and promotes] accountability and citizen participation in decisions on peace and security, social justice and international law.' ${ }^{19}$ GPF's texts have been chosen for the efforts that GPF makes to ensure access of NGOs to the UN. GPF does not seem to have a special interest in any particular area of the work 


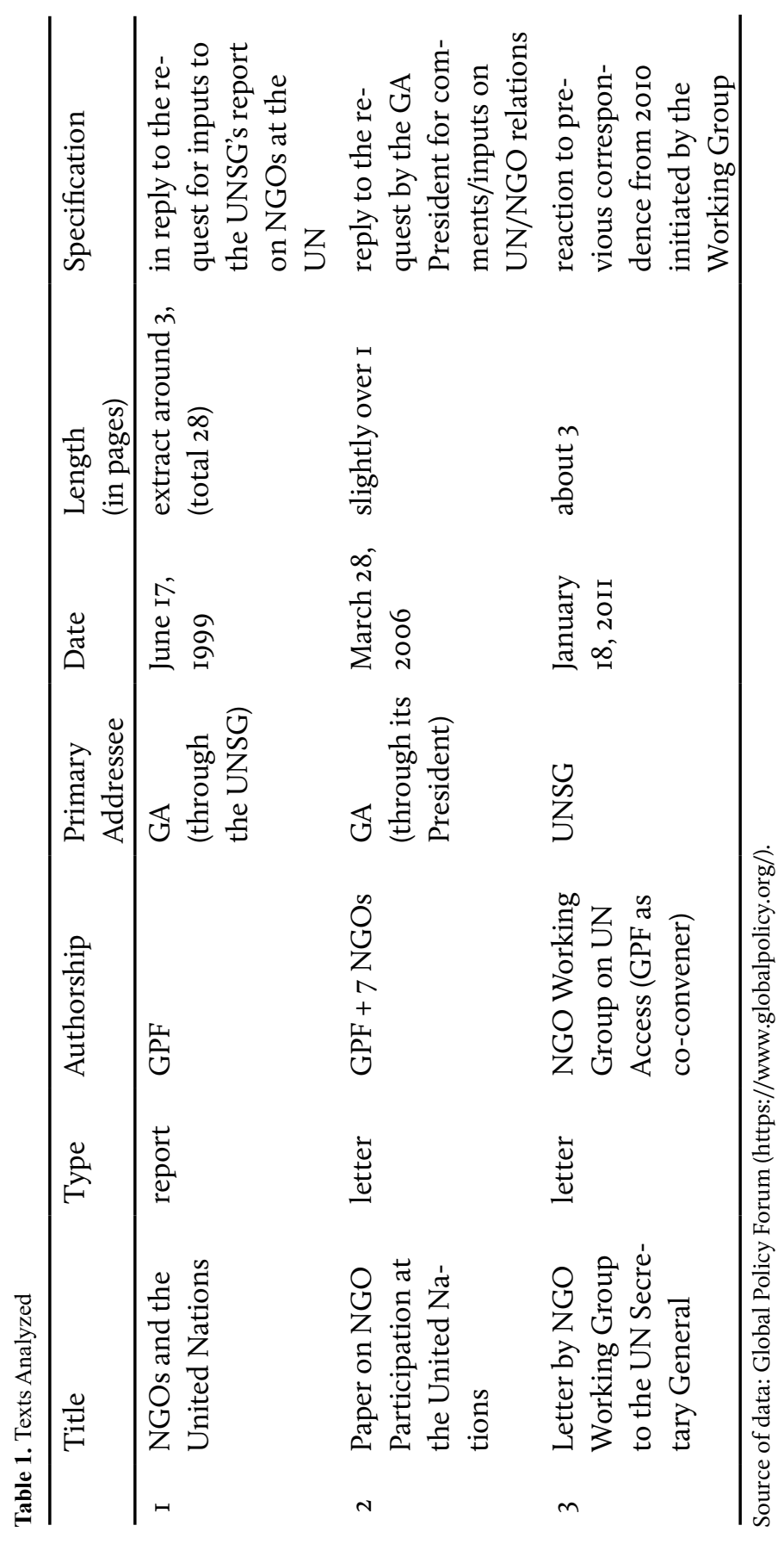

Jaroslava

Bobková 
of the UN than that of promoting its openness to those who are interested in. It is important to stress here that GPF has also established the Working Group on Security Council, which is a successful story of making the Security Council relatively open to NGOs. ${ }^{20}$ As such,

CEJISS development of the GPF discourse, though not necessarily reflecting $\mathrm{I} / 2020$ the position of all NGOs, can be considered broadly representative of the overall NGO discourse on their access to and participation at the $\mathrm{UN}$ and serve well as a basis for assessing the role of NGOs at the UN.

I have decided to choose the three texts from three different periods of time. The historical comparison makes it possible not only to discover potential changes in the GPF discourse in time but also to compare the three discourses to three different social situations on the background of which they were made. I have chosen the three time periods according to relative frequency of texts by GPF published at that time $^{21}$ while considering the fact that these correspond to important moments (explained below) in development of the issue of NGO access to the UN. The three texts were chosen on the above-explained basis independently of their content and form.

The first analysed text is an extract from a 28-page-long report by GPF NGOs and the United Nations. It was prepared in reply to request for inputs to the UN Secretary General's report on NGOs at the UN. The text is dated I7 June 1999. At this period of time, discussion on NGO access to and role within the UN was very intense for it was still soon enough after adoption of the ECOSOC Resolution I996/3I, which had aroused many expectations among NGOs. Given the length of the text, I have limited the focus to 'Introduction', which comprises three chapters. The reason of this choice of extract is mostly practical - the text is not available in its full length (only 15 pages) and according to the content, subsequent parts should only elaborate in more detail what is already briefly mentioned in this extract.

The second analysed text is the Paper on NGO Participation at the United Nations elaborated by GPF in co-authorship with next seven NGOs (Eurostep, Friedrich Ebert Stiftung, North-South Institute, Social Watch, Third World Institute, WEDO and World Federalist Movement). The text is dated 28 March 2006 and is addressed primarily to the President of the General Assembly (GA). The text reacts but is not limited to the issue of the newly born ${ }^{22}$ UN Human Rights Council, a UN body in which many NGOs have had a vital interest (hence also the second selected point of time). 
The third text is a letter by NGO Working Group on UN Access, of which GPF was a co-convener, to the UN Secretary General (UNSG) Ban Ki-moon. The letter is dated I8 January 2011 and reacts to previous correspondence from 20I0. The main theme of the letter and the wider correspondence are perceived negative changes to NGO access to the UN caused by the Capital Master Plan (a six-year renovation project of the UN compound, 2008-I4). The issue elaborated in the text presented another important moment in the NGOs' cause.

The first text, NGOs and the United Nations, is published on the GPF website with a label marking it as 'a comprehensive and critical report that reviews recent progress and problems of NGOs at the UN' and has been prepared as an 'input to the second report of the Secretary General'. The text is a part of a much longer chain of social events going from Decision 1996/297 (accompanying the ECOSOC Resolution 1996/3I that has established new accreditation rules for NGOs) through the first to the second UNSG report (to which this text is an input) submitted for consultation to the GA. It is worth mentioning that while the text by GPF has 28 pages in total, the whole report by the UNSG has only around 22 pages, out of which one and half pages are devoted to recommendations by NGOs. ${ }^{23}$ The analysed text by GPF is primarily addressed to the UNSG, but also to the wider NGO community and the broad public. According to its preface, the aim of the text surpasses its primary purpose of the input to the UNSG report to become a document stimulating further discussion of the matter. Its purpose, stated in the preface, is to speak 'frankly' and 'plainly identify' problems of NGOs at the UN and offer solutions to them.

The second analysed text is also addressed primarily to the UN General Assembly, although this time in a more direct way, through the GA President. The text takes on a form of a letter to the GA President and represents a reply to his request for comments and input on UN/NGO relations. The text, having eight NGOs as authors, is co-authored by GPF. Its length only slightly exceeds one page. It is clearly structured into an introductory paragraph and ten numbered paragraphs, each of them representing one recommendation. Despite being an input on UN/NGO relations, the text does not conceal 'calling for improved NGO access and participation at the UN'. One of the reasons behind the timing of this text seems to be the transformation of Commission on Human Rights to the Human Rights Council that happened by the time of its writing and was heavily discussed by NGOs for their inter- 
est in the field of human rights and efforts to catch the opportunity of the transformation and get as broad participatory rights in the body as possible from its very beginning. This hypothesis seems to be confirmed by the fact that the issue of Human Rights Council appears secCEJISS ond on the list of ten recommendations which create the body of the $\mathrm{I} / 2020$ text, while the first point is rather general in nature.

The last text is presented by GPF as A Letter from the NGO Working Group on UN Access [of which GPF is a co-convenor ${ }^{24}$ ] to the Secretary General Ban Ki-moon. The text is another step by GPF in its long-term effort to provide NGOs with better access to and rights and privileges within the UN system. The letter is dated I8 January $201 \mathrm{I}$ and is about three pages in length. There was similar correspondence between the Working Group and the UNSG in 2010, to which the letter refers. Both letters are mostly focused on the UN Capital Master Plan, which seemed to be the greatest concern of the group at that time and the main motive for the correspondence. The analysed letter of 20II represents a delayed reaction to unsatisfying reply by the UNSG (dated 30 March 20I0) to the previous letter dated 22 February 20I0. It summarises what has been achieved since the last UNSG letter on the basis of 'recommendations' that the UNSG had made in that letter. However, the letter is clearly aimed at showing that more has to be done. The Working Group might have decided to send this letter at a point where it did not see another way forward than to make its cause at the highest level again. The timing may also coincide with the beginning of the year, considered a time of New Year's resolutions and hopes for better results during the upcoming year.

Some differences between texts can be expected automatically. Not only are they elaborated in different periods of time and by a slightly different authorship, but they also take on different forms and have somewhat different aims - to inform how NGOs at the UN work vs. to react to specific problems. However, this does not mean that they are incomparable, especially not if these differences are taken into consideration. Moreover, they also have many common features. All of the texts are at least co-authored by GPF and published on its website (which means that they are addressed also to the wide public); all deal with the question of NGO access to and participation at the UN and have a top UN official as the primary addressee. Rather than complicating comparisons, different social contexts on the background of which the texts have emerged will allow me to show how the GPF discourse 
on NGO access to and participation at the UN was shaped by them and how it might have influenced their next development. Putting it differently, the choice of the texts may prove useful for identifying changing power relations between NGOs and the UN (and its member states) and with that also the role of NGOs at the UN.

Jaroslava

Bobková

\section{Results}

I have analysed the selected texts using the twelve focus areas identified as a basis for discourse text analysis by Fairclough. ${ }^{25}$ Besides a couple of similarities, comparison of the three texts according to these criteria (see Table 2) reveals an important number of differences in analysed traits. However, these must be assessed cautiously and in relevant larger social contexts, for some of the differences may be caused by a slightly different form of the text, its primary addressees, aim and authorship."

To start with similarities in analysed attributes, all the three texts are monothematic - they use only one discourse, which could be labelled as 'discourse of (NGO) participation'. They are focused mostly on activity (rather than knowledge) exchange and on getting results. Their purpose is to show the view of NGOs (other views are largely suppressed) and use it in a way to get for them the best treatment at the $\mathrm{UN}$ as possible (in terms of access or participation rights). To achieve this, the texts use many propositional assumptions pointing to the importance of NGOs for the UN, as well as many value assumptions and other expressions of evaluation. To persuade readers (mainly UN representatives), the authors show strong commitment to the truth (by using assertive statements).

However, development of the role of NGOs at the UN can be read namely from the differing traits. The most striking differences were revealed from analysis of semantic relations, social events representations, modalities, styles, assumptions, evaluations, and to some extent also in discourses (see Table 2).

In terms of semantic relations (relations between meanings of consecutive sentences and clauses), all three texts use mostly the elaborative type. This serves primarily to make recommendations made by NGOs clear. The use of elaborative (rather than temporal) relations in the third text's part summarising past meetings of NGOs with UN representatives is surprising. It proves that authors rather picked up only what their counterparts agreed to, probably in order to make an 


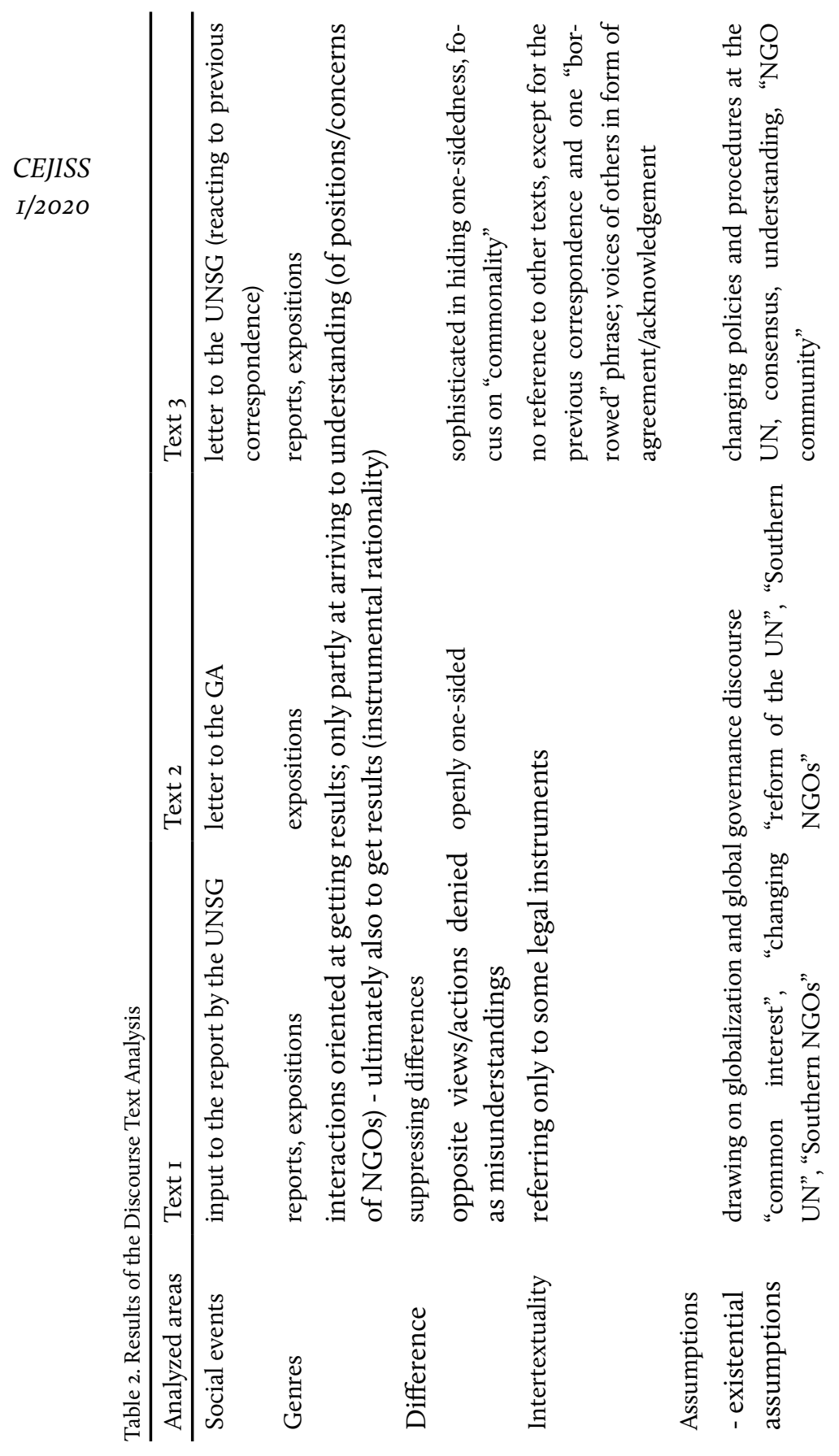




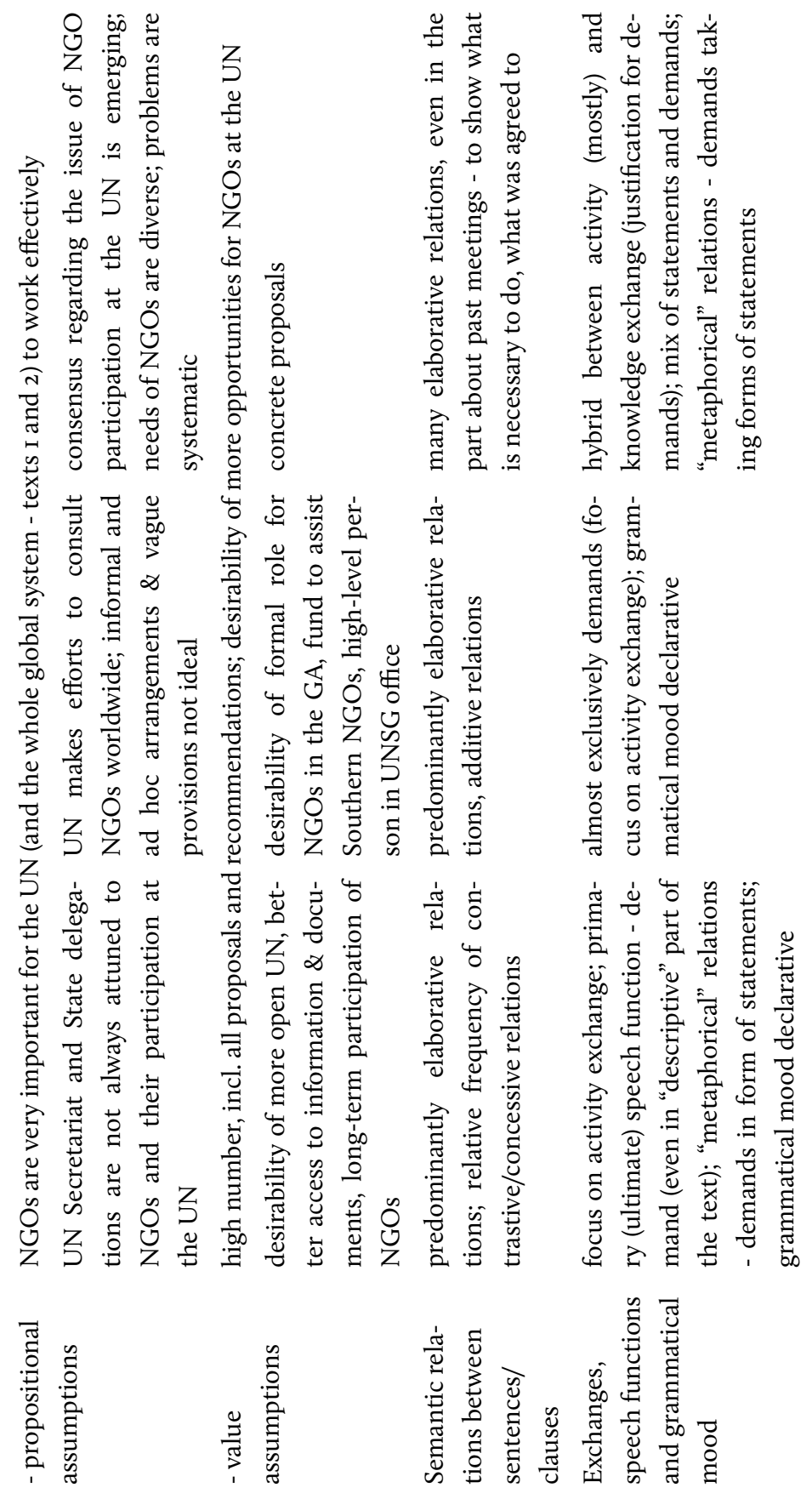




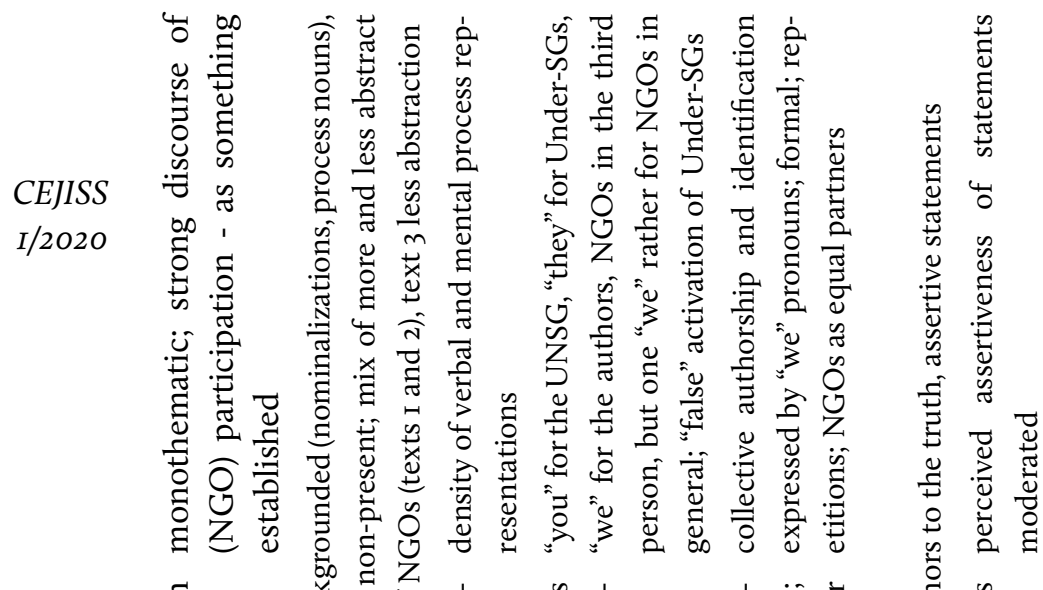

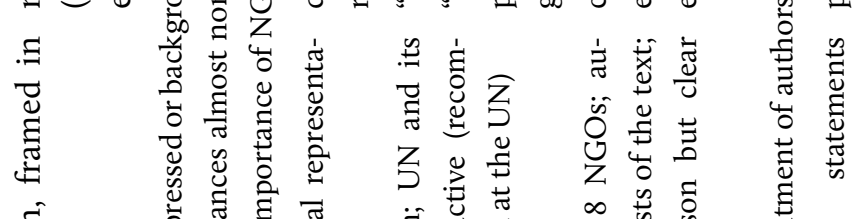

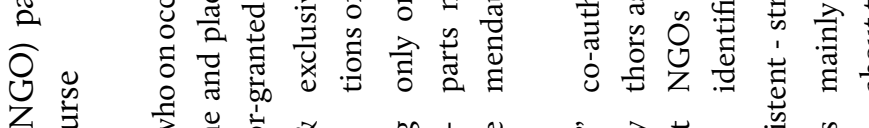

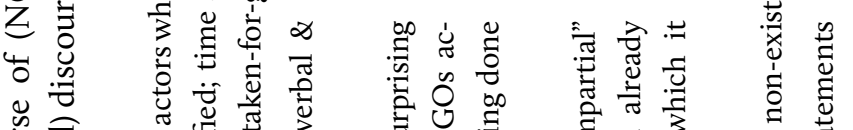

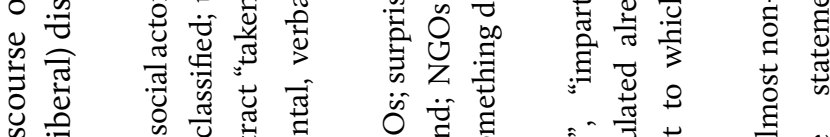

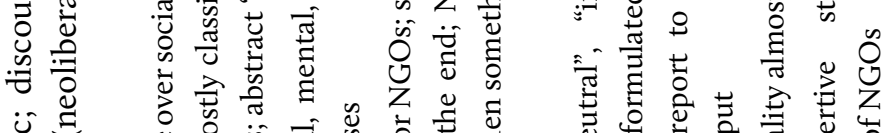

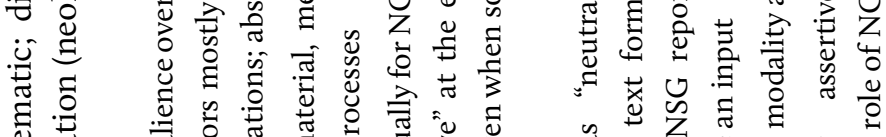

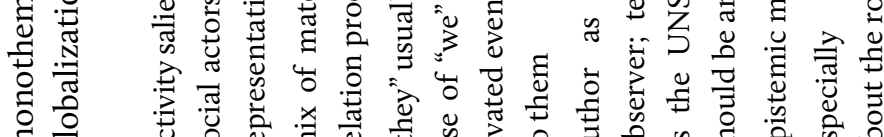

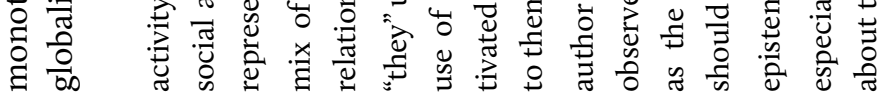

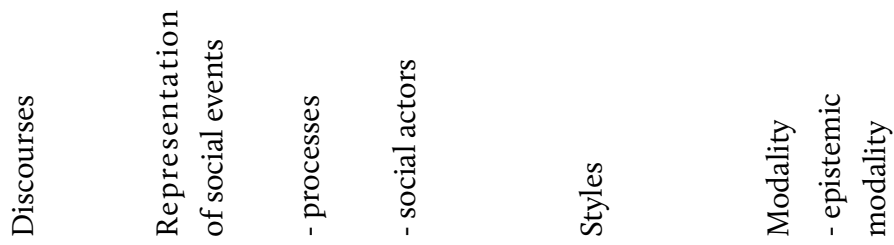




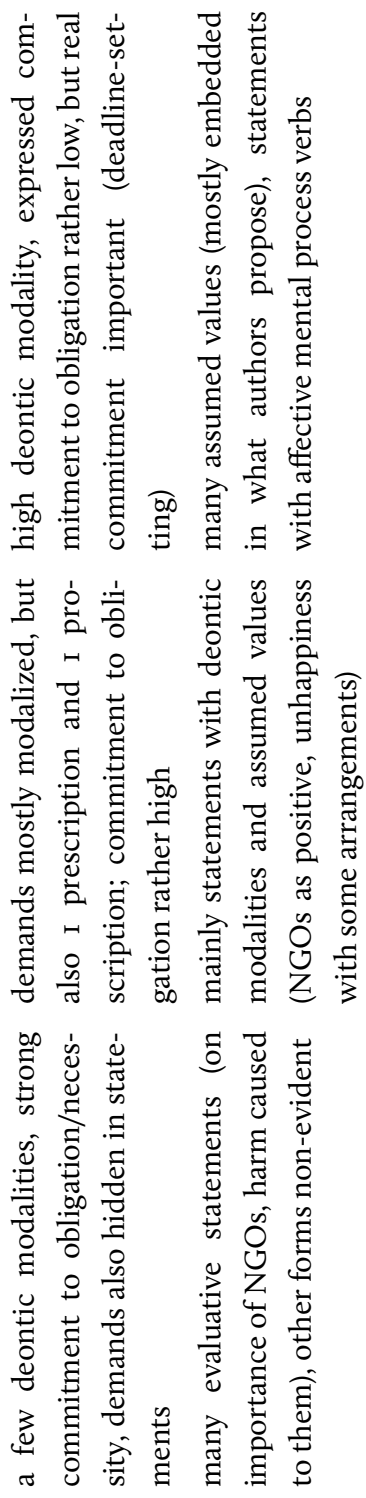

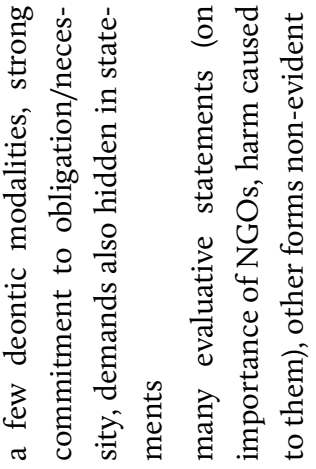

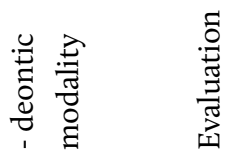


impression of broad support for their demands and to show promises which the addressee's subordinates failed to fulfil. A similar 'manipulation of voices' can be found through analysis of intertextuality (references to other texts and voices) where voices of others in the third CEJISS text take on only a form of agreement with or acknowledgement of I/2020 authors' proposals (deliberately picked up phrases from conversations).

Analysis of social events representation (i.e. how different social events are represented - through syntax, use of vocabulary, word classes, etc.) shows most differences in relation to how social actors have been depicted. All three texts talk about NGOs in the third person, but some identification of authors with them is obvious, especially in the first text. Some inclinations of authors to speak on behalf of all NGOs were, however, detected also in the case of the third text. Despite the aim of authors to show that they distinguish between 'NGOs' (in the third person) and 'the Working Group' (or 'we'), there are two examples that blur this distinction. These are the phrase of 'Nothing about us without us!' and the sentence 'we hope that this concept will prompt the Secretariat to genuinely consult with NGOs in the design, implementation and review of all decisions that affect us'. While in its first part, the sentence makes again the point of distinction between 'we' and 'NGOs', the second half of the sentence blurs this distinction for it speaks about 'decisions that affect us', by which decisions that affect NGOs in general are meant. Based on this evidence, it seems that the authors still probably have some tendency to speak on behalf of all NGOs, but do not feel empowered to do so in an open way, at least not in communication with the UNSG. It is also noteworthy that the first text often activates NGOs (giving them the form of grammatical subject) even where it describes what has happened to them. This might be done with the intention of accentuating their suffering rather than the act itself. The third text, for its part, activates the UN side only in processes of agreeing with authors (I call this a 'false' activation).

In terms of modality (use of epistemic and deontic modals), it is very interesting that all three analysed texts are characterised by strong commitment of authors to the truth (i.e. statements are assertive, with almost no epistemic modality), but differ greatly in terms of commitment to obligation/necessity. Use of deontic modalities varies greatly, going from low (text I) to high (text 3). The first text includes some deontic modals (e.g. 'the UN community should develop a long-term vision'), but most of the demands are rather hidden 
in what appears more as statements. The choice of expressions (it is imperative, must, etc.) makes the commitment of the first text to obligation/necessity almost as strong as the commitment to truth. The second text is made of a set of recommendations which can be classified as demands and thus examined in terms of deontic modalities. One of the headings of the ten recommendations prescribes ('Consult with NGOs Worldwide') and another one proscribes ('Do No Harm'), while the text of the individual recommendations is modalised - saying what 'should' be done. The degree of commitment to obligation expressed by deontic modalities within demands can be classified as rather high, representing something that is required. The demands in the third text are rather highly modalised. There are no prescriptions or proscriptions in the text at all. However, the high deontic modality of the third text may be partly instrumental - to make the authors not look too prescriptive - for their commitment to importance of their demands is expressed differently (e.g. by deadline-setting for proposals). But the third text is sophisticated also in moderating the perceived assertiveness of its statements. This is done primarily by use of introductory clauses to statements, such as 'they agreed that'. Not only can they put some legitimacy to what is proposed, but the necessity of using 'would' instead of 'will' in the past clauses that follow also moderates the perceived assertiveness of the text without lowering the degree of the commitment to the truth. A similar result is achieved through use of noun phrases.

In terms of styles, the first text's analysis reveals efforts of the author to be seen as a neutral observer. By doing this, he might want to show his impartiality to the UNSG so that he considers the text reliable and non-partisan. But it seems that there is also some tendency of the author to write the text as if it was already the UNSG report (rather than just an input). Both the length of the text but also the use of the pronoun 'we' in the final part of the extract (referring to either people in general or GA members) seem to confirm this speculation. The third text's style shows some signs of awareness of strengthened roles for NGOs at the UN. It talks about 'NGO participation at the UN' as something already established and common (discussing rather ways how to improve it rather than the mere concept), uses the phrase of 'consultation with NGOs' (which evokes that NGOs are experts from which the UN should learn) and proposes 'negotiation of consensus solutions in advance' by which it makes clear that NGOs are at least 'equal' partners 
to the UN with which it should negotiate consensus rather than just try to take into account their views, if at all.

\section{Discussion}

CEJISS Cross-assessment of the results of discourse analysis of the three seI/202O lected texts on NGO access to and participation at the UN authored by GPF has revealed several observations. First, it has shown that NGOs have probably achieved a point of saturation in what they may demand from the UN. At least GPF seems to be becoming aware of that they have already achieved probably the maximum possible in terms of participatory rights for NGOs at the UN. Second, there is a clear moderation of tone of the texts over the years, which may be, to some extent, related to the first observation. Third, and not less importantly, realisation of a larger interest among NGOs in the issue of access to and participation at the UN seems to be taking place.

\section{Saturation in NGO demands}

Referring to what I label as 'saturation', it is important to stress that while the first text is obviously soaked by the mood of post-I996-ECOSOC-resolution enthusiasm and expectations, the later texts are increasingly modest in their demands and in confidence of writing. Even though all three texts are aimed at getting results, the exigencies differ substantially. Despite the missing part with recommendations, the analysed introductory excerpt of the first text and the high number of points dealing with problematic issues in the rest of the available part already make it clear that the author demands many improvements for NGOs, although not necessarily that directly as the second text. The second text is modelled as a set of open recommendations (demands), but it is more modest in that it limits itself to ten points. More importantly, the very first recommendation reads 'Do No Harm' which, as a proscription, shows a strong commitment of the authors to necessity (low deontic modality) but does not ask for any new rights or privileges for NGOs. The other recommendations do, but just such formulation of the first recommendation can be interpreted as at least a partial recognition of approaching saturation. The third text is even less assertive. It addresses primarily the only concrete problem linked to the UN Capital Master Plan. Even though the letter informs us that it has been accompanied with a written summary of more proposals (and it is not clear whether they also aim only at this issue), it is 
evident from the text that the authors do not aim at gaining new rights for NGOs but rather at redress of certain problematic arrangements. Its motto 'Nothing about us without us' shows that the main demand of the letter is for the UN to consult NGOs in case of changes that may affect them rather than to make the next changes that NGOs want.

The decline in expectations and extent of demands is evident also Jaroslava from wording of these demands and their time framing. While the first text explicitly asks for more 'access' and even 'new levels of participation' for NGOs, the second one speaks rather of desirability of 'strengthened' participation of NGOs at the UN which may be read as a desire to strengthen what already exists rather than to create something new, which the first text suggests. The third text, for its part, requests the UN 'to genuinely consult with NGOs in the design, implementation and review of all decisions that affect [them]', i.e. not even to strengthen anything rather than to avoid possible worsening of the NGOs' situation. In terms of timing, the first text speaks of need for a vision for 'ten, twenty or even thirty years', whilst the third one is mostly focused on near future (of the upcoming year of 20II). Its shorter time horizon focus is accentuated by the fact that it includes only short-term proposals. This time framing of demands shows a move from strategic broad proposals to more tactical and narrower issues redresses.

Persuasion that NGOs cannot expect any revolutionary changes in their further position at the UN (what the first texts hoped for) can also be one of the reasons why the third text abandons the global governance discourse and assumption of the changing $U N$ presented in previous texts. The third text is more modest also in the way that it does not include the sentence on importance and indispensability of NGOs for the UN (and the whole world) that appeared in the same wording in the first two texts, nor any other form of such explicit praise for NGOs.

\section{Moderation of tone of writing}

Certain decrease in self-confidence is evident also from moderation of tone of the texts. While in the first text, the UN was depicted almost as an antagonist to NGOs (the text explicitly lists problems that the Secretariat has caused to NGOs), the second text refrains from any explicit evaluative statements about the UN and the third one even accentuates the emerging consensus and understanding between the UN and NGOs. The fact that the emphasis on consensus does not re- 
flect strong satisfaction of NGOs with their arrangements at the UN but rather declining self-confidence of the authors is evident in the fact that even the third text still evokes the existence of two 'sides'.

The language in which demands are formulated is also a very imCEJISS portant proof of changes in the overall discourse. Whilst the first text I/2020 mostly focuses on claiming of what is the case, the second one says what should be the case and the third one is mostly about what the authors hope for. The difference has to do with questions of modality. While all three texts are rather assertive as it concerns their statements, the third one is quite successful in trying to moderate its perceived assertiveness by use of introductory clauses and noun phrases. Nonetheless, the greatest difference between the texts concerns their deontic modality. Even though it seems that the authors share a strong commitment to importance of not only what they say but also of what they demand, the openly presented commitment to obligation and assertiveness of demands decline over time when the three texts are compared.

But the decrease in NGO assertiveness and in the scope of their demands does not mean that the power of NGOs and hereby also their role at the UN are diminishing. The texts show rather the contrary. Even though the demanding approach persists, the texts point to problems of non-advancement rather than any regression. Contrarily, some elements of the rising power of NGOs at the UN can be detected. One of them is linked to the question of NGO access to the UNSG. While the first text complains about their impossibility to contact him, the third text is itself a part of conversation with him. Next, whilst the first two texts represent an input which was searched for by the UN, the third text was initiated by the group of NGOs. This is closely linked to one of the ways which Fairclough ${ }^{26}$ considers a proof of exercise of 'power in discourse'. Since it is firstly the UN who sets up the nature and even the timing of interaction with NGOs, whilst later the NGO Working Group acts in an autonomous way, it is possible to claim that the power balance between the UN and NGOs seems to change in favour of the latter.

Given real advancements in NGO position at the UN (rather than any backslides), a conclusion can be made that the observations above are not a sign of growing social distance between the UN and authors (or NGOs for whose rights the authors fight). Instead, it seems that the authors are simply becoming aware of the fact that the existing social 
distance cannot be reduced as much as they might have originally believed.

\section{Acknowledgement of lack of mandate to represent all NGOs}

Furthermore, GPF seems to be getting to acknowledge the fact that it is not the only one or the first amongst more organisations that fights for participatory rights of NGOs at the UN. In the beginning, GPF might have been driven by its initial enthusiasm as well as by its early success of establishing the Working Group on UN Security Council. This is why it could tend to 'write the full report' in I999, while later on it did not try to solve things in such a complex manner but presented just their work. In fact, the third text even openly admits the diversity of NGO needs. ${ }^{27}$ Moreover, unlike the first text, the latter two texts are written in co-authorship of more NGOs. The last one is even written by an established NGO Working Group connecting NGOs with a similar interest (UN access) though not necessarily the same ideas of how to achieve it (which is more likely to be the case of the group of NGOs signed under the second text).

This is closely linked to the observation about the personal identification of the authors with their texts. The first two texts are written in the third person, talking about NGOs as 'they'. Even though the author of the first text is trying to look like a 'neutral' observer, despite the use of the third person, he has tendency to speak on behalf of NGOs. He writes mostly about what NGOs do, or what is done to them, but he also expresses their experience, feelings and thoughts (e.g. 'NGOs are disappointed', 'NGOs feel', 'NGOs were also alarmed'). In the second text, NGOs are mostly passivated (figuring as objects rather than subjects in grammatical terms), so it is not obvious whether the authors have tendency to speak on behalf of them or not. Contrarily, the third text is written mostly in the first-person plural. Despite speaking about NGOs also in general, the authors are making it clear that they do not want to be seen as speaking on behalf of all NGOs (although the internal inclination is still present to a certain extent).

Recognition of diversity of NGOs and their opinions and needs can also be a reason why the authors, who suppress differences in all three texts, are trying to hide this practice in a more sophisticated way in the third text. Shortening and better structuring of texts are another proof of this realisation (as the authors are not the only ones who have something to say about the issue, they must be brief). 


\section{Professionalisation and/or adaptation?}

However, most of these changes in writing, which show increasing sophistication, may also be to some extent a sign of the professionalisation of GPF and development of its art of writing. It may also be

CEJISS the case that in the covered time period, GPF learned to utilise the $\mathrm{I} / 2020$ style of writing which is internal to the UN. At the UN, the discourse can be partly influenced by some intra-institutional rules, or at least some existing practice to which all adjust their discourses - and this can be especially true for NGOs who are eager to show that they are familiar with the UN apparatus and that they are an integral part of it. They have learnt that they need to be concise and precise so that anyone listens to them, that they must sound formal, not to pretend to be more than what they are, show concrete proposals rather than general long-term visions without clear paths of how to achieve them and build their position rather step by step in order not to arouse fears of their growing power and assertiveness.

\section{Conclusion}

In this article, I present discourse analysis as an alternative approach to studying the role of NGOs at the UN. Since the role of NGOs at the UN can be hardly measured in terms of their share in UN outcomes, due to both diversity of factors by which these outcomes are influenced and the diverse and often subtle ways in which NGOs make their part, discourse analysis emerges as an interesting tool to show at least some tendencies in development of the role of NGOs at the UN. This approach is based on a turn from purely institutionalist views on the issue to larger considerations of capacity of discourse to socially construct but also reflect on relations between individual actors and their roles.

To show the approach in a practical manner and to test both its feasibility and capacity to bring results, the article has presented its application to three texts on UN access to and participation at the UN authored or co-authored by Global Policy Forum, an NGO which has the fight for more participatory rights for NGOs at the UN as one of its main missions. Both the author (GPF) and its texts have been chosen independently of expressed attitudes towards the analysed issue. The selected texts come from different time periods (I999, 2006, 201I) so that a historical comparison could be made and possible trends in development of the discourse (and hence also the role of NGOs at the 
UN) discovered. To analyse the texts, I have adopted the approach developed by Fairclough. ${ }^{28}$ I consider this approach a useful tool not only because of its focus on the field of social science, but also because of the simple fact that choice of a concrete approach in advance to the real analysis of texts can limit the potential bias of a researcher.

By employing this approach practically, some important observations have been revealed regarding the role of NGOs at the UN, which can serve as a basis for further research. Firstly, they have shown that there seems to be a kind of saturation in what GPF feels that it may demand for NGOs from the UN in terms of their access and participatory rights. Secondly, it seems that GPF is becoming aware of the fact that more NGOs are now interested in not only the mere work of the UN but also the way NGOs are treated at the organisation. Thirdly, in spite of the real advancements of NGOs, GPF is taking on a more moderate tone in communication with the UN. Some professionalisation in its discourse can also be observed.

All of these findings are closely linked to the question of the role of NGOs at the UN. The most important finding is the revealed process of saturation of NGO demands or at least realisation of this process by GPF. The analysed texts have shown that GPF is increasingly aware of the fact that the current situation of NGOs at the UN will not be subject to substantial changes anymore. The saturation may also be the reason for the dissolution of the Working Group on UN Access. ${ }^{29}$ At the same time, however, it seems that the position of NGOs at the UN has been strengthened. In earlier times, it was a problem accessing the UNSG (the first text makes this clear) and it was possible to address him only upon his own request (for inputs), while correspondence with him has become a common matter over the time (it is the case of the third text and the social events of which this text is a part). Moreover, earlier inputs written upon a request seem to be replaced by a more proactive approach from the NGOs side. This is clear proof of lowering the social distance between the UN and NGOs and of the relative power imbalance. Also, the relations between NGOs and the UN have improved - from those characterised as antagonistic to more cooperative relations as in between understanding partners. The analysis has also shown that there is a greater diversity of NGOs who seem to be active in promoting NGO participatory rights at the UN than before.

In conclusion, this practical exercise has indicated that the role of NGOs at the UN seems to be somewhat strengthened from the turn of 
the century. From the perspective of GPF, NGOs appear to have transformed from entities begging for more access to more equal partners. The example of GPF shows that NGOs also seem to have started to act as such. They communicate in a more formal and sophisticated way

CEJISS and try to address rather concrete issues and focus on tangible results I/2020 rather than to follow idealistic dreams and shout for nearly the same treatment which the governments have. This 'sobering-up' means moderation not only in content of demands, but also in assertiveness and tone in which they are formulated.

The findings of this analysis serve not only as an insight into the mere issue of the role of NGOs at the UN, but, above all, they are themselves an evaluation of the employed approach, which this article presents as a new, alternative way of how to understand the issue. So far, the role of NGOs in intergovernmental organisations has been assessed primarily on the basis of estimation of NGOs share in these organisations' outcomes. However, I show in this article that even the best estimates do not have to be reliable reflections of reality. Even scholars whose focus goes beyond comparing the outcomes with NGO preferences (which may be rather a coincidence than necessarily a proof of influence) to analyse also the activities leading to these outcomes may find it difficult to assess the overall influence of NGOs especially because of their diverse interests and different tactics they use to exercise it.

One of the alternative approaches to assess the influence and more generally the role of NGOs is discursive analysis. The use of discursive analysis approach for assessing the role of NGOs at the UN assumes that relations between actors and their respective roles are socially constructed. Discourse not only does socially construct the role of NGOs at the $\mathrm{UN}^{30}$ but can also depict it. The demonstration analysis of three texts authored by GPF has proved the capacity of discourse analysis to reveal signs of power (hidden in or behind the discourse) that constitute the power relations between NGOs and the UN and the role which NGOs play within the UN. The historical comparison has helped me to show how this role embodied in the GPF discourse evolved over the years.

Even though further research is needed to justify these preliminary findings on the role of NGOs at the UN and to fully understand the issue, the article represents an important step forward as it shows an alternative way to examine it. It has also proved that this approach 
is workable and can generate important observations. Yet to understand better the role of NGOs at the UN and its possible implications, a widening of the presented study would be advisable. The presented approach can be used for adding the perspective of next NGOs but also that of the UN representatives and of member states to the overall picture. Despite its proven capacity to bring results and to overcome difficulties faced by other approaches, it is also important to admit that the discourse analysis is itself just one of many perspectives which can hardly uncover all issues at stake. As such, it is recommended not to renounce searching for new ways of dealing with this important issue, which could enrich the findings obtained in previous studies and also those achieved through the method presented in this study.

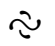

The article has been prepared under the institutional support of the Faculty of International Relations, University of Economics, Prague.

Jaroslava BobKová is affiliated with the Faculty of International Relations at the University of Economics in Prague (Jan Masaryk Centre for International Studies). She also works as a diplomat at the Ministry of Foreign Affairs of the Czech Republic. Her practical knowledge of NGO engagement at the United Nations derives mostly from her work experience from the Permanent Mission of the Czech Republic to the United Nations Office and other international organisations in Geneva. Her research includes theory of neoliberal institutionalism, social constructivism, interactions between non-governmental and intergovernmental organisations, as well as role of non-state actors in globalisation and global governance. She has published her articles both in the Czech Republic and abroad. The author can be contacted at jaroslava.bobkova@vse.cz.

\section{Endnotes}

I See, for instance, Kenneth Anderson (20II), "Accountability' as 'legitimacy': global governance, global civil society and the United Nations,' Brooklyn Journal of International Law 36(3), pp. 84I-90; Thomas G. Weiss, D. Conor 
Seyle and Kelsey Coolidge (2013), The Rise of Non-State Actors in Global Governance: Opportunities and Limitations, Broomfield: One Earth Future Foundation; Bruce Cronin (2002), 'The Two Faces of the United Nations: The Tension Between Intergovernmentalism and Transnationalism,' Global Governance 8(I), pp. 53-7I.

CEJISS 2 Peter Willetts (2000), 'From 'Consultative Arrangements' to 'Partnerships': I/202O The Changing Status of NGOs in Diplomacy at the UN,' Global Governance 6(2), pp. I9I-2I2.

3 See, for example, Chadwick F. Alger (2002), 'The emerging roles of NGOs in the UN system: From Article 7I to a people's millennium assembly,' Global Governance 8(I), pp. 93-II7; Claire Breen (2005), 'Rationalising the Work of UN Human Rights Bodies or Reducing the Input of NGOs? The Changing Role of Human Rights NGOs at the United Nations,' Non-State Actors and International Law 5(2), pp. IOI-I26; Dianne Otto (I996), 'Nongovernmental Organizations in the United Nations System: The Emerging Role of International Civil Society, Human Rights Quarterly I8(I), pp. I07-I4I.

4 They either derive the role of NGOs from simple presence of an idea promoted by them - e.g. Wendy Guns (2013), 'The Influence of the Feminist Anti-Abortion NGOs as Norm Setters at the Level of the UN: Contesting UN Norms on Reproductive Autonomy, I995-2005, Human Rights Quarterly 35(3), pp. 673-700; or they focus rather on ways how to boost the NGO role - e.g. Barbara Gemmill and Abimbola Bamidele-lzu (2002), 'The Role of NGOs and Civil Society in Global Environmental Governance,' in Daniel C. Esty and Maria H. Ivanova (eds.) Global Environmental Governance: Options \& Opportunities, New Haven, CT: Yale Center for Environmental Law \& Policy, pp. 77-Ioo; Lucia Nader (2007), 'O papel das ONGs no Conselho de Direitos Humanos da ONU,' Sur. Revista International de Direitos Humanos 4(7), pp. 6-27.

5 See, for instance, Ann Marie Clark, Elisabeth J. Friedman, and Kathryn Hochstetler (1998), 'The Sovereign Limits of Global Civil Society: A Comparison of NGO Participation in UN World Conferences on the Environment, Human Rights, and Women,' World Politics 5I(I), pp. I-35; Sara Edge and John Eyles (2015), 'Contested Governmentalities: NGO enrollment and influence over chemical risk governance rationales and practices,' Environmental Policy and Governance 25(3), pp. I88-200; David Humphreys (2004), 'Redefining the Issues: NGO Influence on International Forest Negotiations,' Global Environmental Politics 4(2), pp. 5I-74.

6 As two examples of these efforts see Bob Reinalda (20II), The Ashgate research companion to non-states actors, Burlington, VT: Ashgate Pub. Co.; Peter Willetts (20II), Non-Governmental Organizations in World Politics: The Construction of Global Governance, New York: Routledge.

7 Norman Fairclough (2003), Analysing discourse textual analysis for social research, London: Routledge.

8 On this issue see, for instance, Rachel Brett (I995), 'The role and limits of human rights NGOs at the UN,' Political Studies 43(I), pp. 96-IIo.

9 On the socially constructive capacity of discourse, see, for example, Ruth Wodak et al. (1999), The Discursive Construction of National Identity, Edinburg: Edinburgh University Press, p. 8.

Io Sheldon Stryker, and Ann Statham (I985) 'Symbolic Interactionism and Role Theory' in Gardner Lindzey and Elliot Aronson (eds.) The Handbook of Social Psychology, 3rd ed. New York: Random House, pp. 3II-378. 
II The criterion of self-perception was used as a complementary tool e.g. in the study by Andreas Dür and Dirk De Bièvre (2007), 'Inclusion without Influence? NGOs in European Trade Policy,' Journal of Public Policy 27(I), pp. 79-IOI.

I2 Norman Fairclough (I989), Language and power, London: Longman, p. 43.

I3 On complexity of the relationship between NGO participation and influence see Charlotte Dany (2014), 'Janus-faced NGO Participation in Global Governance: Structural Constraints for NGO Influence,' Global Governance 20(3), pp. 4I9-436; Sara Edge and John Eyles (2015), 'Contested Governmentalities: NGO enrollment and influence over chemical risk governance rationales and practices, Environmental Policy and Governance 25(3), pp. 188-200.

I4 For detailed study on this issue see Jonas Tallberg and Christer Jönsson (eds.) (20I0), Transnational Actors in Global Governance: Patterns, Explanations, and Implications, Basingstoke: Palgrave Macmillan.

I5 Fairclough (2003).

I6 Fairclough (2003).

I7 James A. Paul (I999), 'NGOs and the United Nations: Comments for the Report of the Secretary General', Global Policy Forum, June, available at <www.globalpolicy.org/images/pdfs/images/pdfs/ngos_and_the_united_ nations.pdf> (accessed I5 August 20I7); Eurostep et al. (2006), 'Paper on NGO Participation at the United Nations,' Global Policy Forum, 28 March, available at <www.globalpolicy.org/component/content/article/I77/31756. html $>$ (accessed I3 July 20I7); NGO Working Group on U.N. Access (20II), 'Letter from the NGO Working Group on UN Access to the Secretary General Ban Ki -moon New York,' Global Policy Forum, I8 January,available at <www.globalpolicy.org/images/pdfs/images/pdfs/S-G_letter_on_UN_ access_Jan_20II.pdf $>$ (accessed I7 August 20I7).

I8 Among the proves of its salience in the matter until these days it can be noted that its website is among the top results displayed by Google search engine when the combination of 'NGOs' and 'the United Nations' is entered in the searching line.

I9 Global Policy Forum (2017), 'About us', available at <https://www. globalpolicy.org/about-gpf-mm.html $>$ (accessed 23 April 2017).

20 The Working Group on Security Council, founded in I995, is an NGO forum at the UN intermediating regular interaction of NGOs with Council members at the highest level.

2I Years I999 and 2006, when the first two texts were published, are along with the year of 2005 the years of the most important reports (co-)authored by GPF as the section of its website devoted to the issue of 'Relations between NGOs and the UN' suggests. The year of 20II, when the third analyzed text is dated, is among the top recent years in terms of the number of GPF's articles on access of NGOs to the UN and their mutual relations.

22 The United Nations Human Rights Council was established by the resolution of the General Assembly (A/RES/6o/25I) adopted on I5 March 2006.

23 Even though NGOs' recommendations are ranked as last in the SG report, they have been given the most space (I,5 pages compared to I page devoted to member states' recommendations and a half page for recommendations by UN specialised agencies and intergovernmental organisations). Moreover, they touch upon most of the issues dealt with in the analyzed text by GPF. 
24 The group was established in 2009 with the aim to advocate 'for a positive and open partnership between the United Nations and NGOs'. It was regrouping NGO representatives who had been 'active over many years on access issues', mostly those based at the UN headquarters in New York. As of September 20II, the Working Group comprised I3 representatives of I2

CEJISS organisations (GPF had 2 members, its executive director and a program $I / 2020$ coordinator), at the time of the letter writing, it had just nine members. As of 20I6, the Working Group did not exist any longer.

25 Fairclough (2003), pp. I9I-I94.

26 Fairclough (1989), p. 45.

27 It speaks about 'diversity and range of needs of members of the international NGO community'.

28 Fairclough (2003).

29 The information about dissolution of the Working Group was confirmed by e-mail from Soon-Young Yoon, First Vice-President of the Conference of NGOs in consultative relationship with the UN (CoNGO), organisation which was convener of the Working Group.

30 This finding is useful not only for scholars, but also for practitioners, be it representatives of NGOs, international organisations or their member states, for whom it is important to realise the power which their 